\title{
ANALISIS PERBEDAAN PERSEPSI KONSUMEN TERHADAP KUALITAS PRODUK MIE GORENG MERK MIE SEDAAP DAN INDOMIE
}

\author{
Oleh: \\ Sri Gustini \\ STIE Rahmaniyah Sekayu \\ srigustini.mudrik@gmail.com
}

\begin{abstract}
ABSTRAK
Penelitian ini bertujuan untuk mengetahui Perbedaan Persepsi Konsumen Terhadap Kualitas Produk Mie Goreng Merk Mie Sedaap dan Indomie Di Kecamatan Lais.Sampel yang digunakan dalam penelitian ini sebanyak 100 responden yang ditentukan dengan rumus Maholtra.Sampel diambil dengan menggunakan teknik Nonprobability sampling dengan pendekatan accidental sampling (pengambilan sampel berdasarkan kebetulan).Teknik pengumpulan data yang digunakan adalah kuesioner dan observasi.Data diolah dan dianalisis dengan analisis regresi linier sederhana dan analisis korelasi menggunakan Statistical Package for Social Science (SPSS). Hasil penelitian menunjukkan bahwa (1) persepsi konsumen berpengaruh secara signifikan terhadap kualitas Produk mie goreng merek mie sedaap dan indomie di Kecamatan Lais dengan sig thitung $<\operatorname{sig} \alpha(0.000<0.005)$; (2) nilai koefisien korelasi sebesar 0,447 menunjukkan bahwa terjadi hubungan atau korelasi yang sedang antara persepsi konsumen terhadap kualitas produk mie goreng merek mie sedaap dan indomie di Kecamatan Lais, sedangkan nilai adjusted $R$ square sebesar 0,200 menunjukkan bahwa persepsi konsumen mempengaruhi kualitas produksebesar $20 \%$.
\end{abstract}

Kata Kunci: Persepsi Konsumen, Kualitas Produk

\section{PENDAHULUAN}

Era globalisasi telah menuntut adanya perubahan paradigma lama dalam segala bidang, salah satunya adalah bidang pemasaran.Semakin tingginya tingkat persaingan di bisnis lokal maupun global dan kondisi ketidakpastian memaksa perusahaan untuk mencapai keunggulan kompetitif agar mampu memenangkan persaingan di bisnis global.

Pesaing yang dihadapi sebuah industri tidak datang dari kawasan atau wilayah geografis setempat, tetapi raksasa global dari mancanegara hadir untuk saling berebut pasar. Setiap industri mengalami globalisasi yang dipicu oleh 4 (empat) faktor utama yaitu pelanggan (customers), biaya (cost), negara (country) dan persaingan (competition). Oleh karena itu, bagi perusahaan yang mempunyai keinginan untuk memenangkan persaingan tersebut harus mampu menjaring konsumen agar perusahaan mampu bertahan 
hidup. Untuk menjaring konsumen diperlukan suatu strategi, hendaknya perusahaan mengidentifikasikan keinginan konsumen yang belum dipuaskan, dengan cara menentukan barang yang hendak diproduksi, menentukan cara promosi, menentukan harga yang tepat, dan memilih saluran distribusi. Jadi, kegiatan pemasaran merupakan suatu proses yang saling berhubungan sebagai suatu sistem.

Menurut Suryani, (2012: 97), Persepsi Konsumen adalah sebagai proses dimana individu memilih, mengorganisasikan dan mengintepretasikan stimuli menjadi suatu yang bermakna. Menurut Kotler dan Amstrong (2012:325), Kualitas Produkadalah Segala sesuatu yang dapat ditawarkan ke pasar untuk mendapatkan perhatian, dibeli, digunakan, atau dikonsumsi yang dapat memuaskan keinginan atau kebutuhan.

Produk mie instan merupakan salah satu makanan yang sudah tidak asing bagi masyarakat Indonesia, bahkan produk mie instan memiliki stigma yang identik dengan gaya hidup mahasiswa yang tinggal di kost-kostan. Mie instan sering dikonsumsi sebagai makanan alternatif pengganti makanan pokok.Perkembangan produk mie instan yang sudah dianggap sebagai makanan cepat saji dan bahkan sebagai makanan pokok menyebabkan tingkat persaingan pada industri mie instan ini semakin tinggi. Dalam suasana persaingan yang semakin ketat, produsen mie instan berusaha memasarkan produknya dengan cara melakukan promosi yang gencar untuk menawarkan keunggulan produknya.

Mie Sedaap merupakan mie instan yang diproduksi oleh Wings Food sejak 2003. Pada awal diluncurkan, varian rasa Mie Sedaap hanya ada tiga varian, yaitu Mie Goreng dengan "kriuk-kriuk" (bawang gurih renyah), Rasa Soto dengan "koya" (serbuk gurih) dan Rasa Ayam Bawang dengan bawang goreng (Wings food, 2003).

Indomie Mi Goreng merupakan salah satu tipe mi instan yang dibuat dengan merek Indomie oleh perusahaan Indofood, penghasil mi instan terbesar di dunia yang terletak di Indonesia. Mie instan ini menjadi makanan pokok bagi siapapun yang pendapatannya kecil dan sudah menjadi makanan favorit di Australia, Asia dan negaranegara Eropa Pada tahun 2006, Indomie meluncurkan Indomie Mi Goreng Kriuuk 8x. Arti $8 \mathrm{x}$ di produk ini adalah "Lebih banyak, Lebih renyah, hadir dalam tiga rasa, yaitu Ayam, Bawang, Pedas.Pada tahun 2012 Indomie meluncurkan Indomie Mi Goreng 
Cabe Ijo dengan tagline "Ijo, mantap, hot".Varian rasa baru, Mi Goreng Rasa Dendeng Balado sudah diluncurkan sebagai bagian dari Indomie Kuliner Indonesia pada bulan September 2014. Pada tahun 2016, Indomie meluncurkan varian baru, Mie Goreng Rasa Kuah, hadir dalam dua rasa, yaitu Mi Goreng Rasa Soto dan Mi Goreng Rasa Ayam Bawang, serta meluncurkan varian baru Indomie Real Meat, hadir dalam dua rasa, yaitu Mi Goreng Ayam Jamur dan Mi Goreng Rendang (Indofood, 2009).

Saat ini produk mie intan sudah memiliki berbagai varian rasa dan kemasan.Di kecamatan Lais sendiri selain mie goreng, juga terdapat mie instan lainnya seperti mie sayur, mie gelas, pop mie dll.Persepsi konsumen mengenai kualitas inilah yang mempengaruhi masyarakat Kecamatan Lais mengkonsumsi mie goreng.Dengan demikian tujuan dari penelitian ini adalah untuk mengetahui pengaruh persepsi konsumen terhadap kualitas produk mie goreng merek mie sedaap dan indomie di Kecamatan Lais.

\section{LANDASAN TEORI \\ Persepsi Konsumen}

Menurut Suryani (2012: 97), persepsi konsumen adalah sebagai proses dimana individu memilih, mengorganisasikan dan mengintepretasikan stimuli menjadi suatu yang bermakna.

\section{Indikator Persepsi Konsumen}

Menurut Kotler (2012: 237), faktor-faktor yang mempengaruhi persepsi konsumen yaitu:

1. Penglihatan

Tanggapan yang timbul atas rangsangan akan sangat dipengaruhi oleh sifatindividu yang melihatnya. Sifat-sifat yang mempengaruhi persepsiadalah (1) Sikap, (2) Motivasi dan (3) Minat.

2. Pengalaman Masa Lalu

Hal ini dapat mempengaruhi persepsi seseorang karena orang biasanya akan menanamkan kesimpulan yang sama dengan apa yang pernah dilihat,didengar ataupun yang dialami seperti (1) Sasaran dan (2) Situasi. 


\section{Kualitas Produk}

Menurut Kotler dan Amstrong (2012: 223), kualitas produk adalah kemampuan sebuah produk dalam memperagakan fungsinya, hal itu termasuk keseluruhan durabilitas, reliabilitas, ketepatan, kemudahan pengoperasian dan reparasi produk juga atribut produk lainnya.

\section{Indikator Kualitas Produk}

Indikator Kualitas produk menurut Kotler dan Amstrong (2012: 325) adalah:

1. Kinerja, berhubungan dengan karakteristik operasi dasar dari sebuah produk.

2. Daya tahan yang berarti berapa lama atau umur produk yang bersangkutan bertahan sebelum produk tersebut harus diganti. Semakin besar frekuensi pemakaian konsumen terhadap produk maka semakin besar pula daya produk.

3. Kesesuaian dengan Spesifikasi, yaitu sejauh mana karakteristik operasi dasar dari sebuah produk memenuhi spesifikasi tertentu dari konsumen atau tidak ditemukannya cacat pada produk.

4. Fitur, adalah karakteristik produk yang dirancang untuk menyempurnakan fungsi produk atau menambah ketertarikan konsumen terhadap produk.

5. Reliabilitas adalah probabilitas bahwa produk akan bekerja dengan memuaskan atau tidak dalam periode waktu tertentu. Semakin kecil kemungkinan terjadinya kerusakan maka produk tersebut dapat diandalkan.

6. Estetika berhubungan dengan bagaimana penampilan produk.

7. Kesan Kualitas merupakan hasil dari penggunaan pengukuran yang dilakukan secara tidak langsung karena terdapat kemungkinan bahwa konsumen tidak mengerti atau kekurangan informasi atas produk yang bersangkutan.

8. Perbaikan meliputi kecepatan dan kemudahan untuk direparasi, serta kompetensi dan keramahtamahan staf layanan.

\section{Faktor yang Mempengaruhi Kualitas Produk}

Baum (2011: 28), menyatakan faktor yang mempengaruhi kualitas produk ada 9 faktor yang dikenal dengan 9M, yaitu : Market (pasar), Money (Modal), Management (manajemen), Men (sumber daya manusia), Motivation (motivasi), Matherial, Machine and Mechanization (bahan, mesin dan mekanisasi), (metode informasi modern), Mounting product requirement (persyaratan proses produksi).

\section{METODE PENELITIAN}

Desain penelitian yang digunakan penulis dalam penelitian ini adalah Penelitian eksperimen yang merupakan penelitian yang digunakan untuk mencari perbedaan 
perlakuan tertentu terhadap yang lain dalam kondisi yang terkendalikan. Kondisi yang terkendalikan dimaksud adalah adanya hasil dari penelitian dikonversikan ke dalam angka-angka, untuk analisis yang digunakan dengan menggunakan analisis statistik.

Populasi dalam penelitian ini adalah seluruh konsumen yang mengkonsumsi Mie Sedaap Goreng dan Indomie Goreng di Kecamatan Lais yang terdiri dari 14 desa diantaranya: Danau Cala, Epil, Lais, Petaling, Purwosari, Rantau Keroya, Tanjung Agung Barat, Tanjung Agung Selatan, Tanjung Agung Timur, Tanjung Agung Utara, Teluk, Teluk Kijing I, Teluk Kijing II, dan Teluk Kijing III. Jumlah populasi dalam penelitian ini tidak dapat diidentifikasi jumlahnya.

Menurut Sugiyono (2012: 62), sampel adalah bagian dari jumlah dan karakteristik yang dimiliki oleh populasi. Sedangkan Menurut Malhotra (2013: 135), besarnya jumlah sampel yang diambil dapat ditentukan dengan mengalihkan jumlah pertanyaan kuesioner dengan 5 (lima) atau $5 \mathrm{X}$ jumlah pertanyaan kuesioner. Dalam penelitian ini jumlah pertanyaan kuesioner sebanyak 20 pertanyaan. Jadi jumlah kuesioner dalam penelitian ini sebanyak 100 responden $(5 \times 20=100)$ dengan menggunakan teknik Non-probability sampling dengan pendekatan accidental sampling (pengambilan sampel berdasarkan kebetulan).

Pengumpulan data dalam penelitian ini menggunakan teknik observasi dan kuesioner. Jawaban atas pertanyaan dalam kuesioner disusun berdasarkan skala likert.

Data yang telah dikumpulkan kemudian diolah agar memiliki makna untuk menjawab permasalahan yang diteliti. Kemudian dilakukan pengujian validitas dan reliabilitas dengan menggunakan SPSS.

Model kerangka berfikir yang dikembangkan untuk mengetahui faktor-faktor yang mempengaruhi persepsi konsumen terhadap kualitas produk mie goreng merek mie sedaap dan indomie di Kecamatan Lais.

Persepsi Konsumen (X)

1. Penglihatan

2. Pengalaman Masa Lalu

Suryani (2012:97)
Kualitas Produk (Y)

1. Kinerja

2. Daya tahan

3. Kesesuaian

4. Fitur

5. Reliabilitas

6. Estetika

7. Kesan Kualitas

8. Perbaikan

Kotler dan Amstrong(2012: 223) 


\section{Gambar 1.Kerangka Berfikir}

Dari kerangka berfikir di atas dapat dijelaskan operasionalisasi penelitian ini.

\section{Tabel 1.Definisi Operasional}

\begin{tabular}{|c|c|c|c|}
\hline Variabel & Definisi Variabel & Indikator & $\begin{array}{c}\text { Item } \\
\text { Pernyataan }\end{array}$ \\
\hline $\begin{array}{l}\text { Persepsi } \\
\text { Konsumen } \\
\text { (X) }\end{array}$ & $\begin{array}{lr}\text { Sebagai proses dimana } \\
\text { individu } \\
\text { mengorganisasikan dan } \\
\text { mengintepretasikan } \\
\text { stimuli menjadi suatu } \\
\text { yang bermakna. } \\
\text { Suryani (2012: 97) }\end{array}$ & $\begin{array}{l}\text { 1.Penglihatan } \\
\text { a. Sikap } \\
\text { b. Motivasi } \\
\text { c. Minat } \\
\text { 2. Pengalaman Masa Lalu } \\
\text { a. Sasaran } \\
\text { b. Situasi }\end{array}$ & $\begin{array}{c}1 \\
2-3 \\
4-6 \\
\\
7-8 \\
9-10\end{array}$ \\
\hline $\begin{array}{l}\text { Kualitas } \\
\text { Produk } \\
\text { (Y) }\end{array}$ & $\begin{array}{l}\text { Arti dari kualitas produk } \\
\text { adalah kemampuan } \\
\text { sebuah produk dalam } \\
\text { memperagakan fungsinya. } \\
\text { Kotler dan Amstrong } \\
(2012: 325)\end{array}$ & $\begin{array}{ll}\text { 1. } & \text { Kinerja } \\
\text { 2. } & \text { Daya tahan } \\
\text { 3. Kesesuaian } \\
\text { 4. Fitur } \\
\text { 5. Reliabilitas } \\
\text { 6. Estetika } \\
\text { 7. Kesan Kualitas } \\
\text { 8. } & \text { Perbaikan }\end{array}$ & $\begin{array}{c}1 \\
2-3 \\
4 \\
5 \\
6 \\
7 \\
8-9 \\
10\end{array}$ \\
\hline
\end{tabular}

Tenik analisis yang digunakan adalah regresi linier sederhana. Rumus yang digunakan adalah:

$\mathrm{Y}=\mathrm{a}+\mathrm{bX}$ (Sunyoto, 2013: 110

Keterangan:

$$
\begin{aligned}
& Y=\text { Variabel dependen (Kualitas Produk) } \\
& a=\text { Konstanta } \\
& b=\text { Koefisien garis regresi } \\
& X=\text { Variabel independen (Persepsi Konsumen) }
\end{aligned}
$$

\section{HASIL PENELITIAN DAN PEMBAHASAN Karakteristik Responden}

Berdasarkan hasil pengumpulan data yang diperoleh melalui kuesioner yang disebarkan kepada masyarakat Desa Tanjung Agung Barat Kecamatan Lais Kabupaten Musi Banyuasin sebagai responden, maka dapat diketahui karakteristik setiap responden. Karakteristik/identitas responden ini berdasarkan jenis kelamin dan usia.

Tabel 2.Karakteristik Responden

\begin{tabular}{|l|l|c|c|c|}
\hline \multicolumn{2}{|c|}{ Karekteristik } & Jumlaah & Persentasi (\%) & Total \\
\hline \multirow{2}{*}{ Jenis kelamin } & Laki-laki & 57 & 57 & \multirow{2}{*}{100} \\
\cline { 2 - 4 } & Perempuan & 43 & 43 & \\
\hline Usia & $<18$ & 60 & 60 & \multirow{2}{*}{100} \\
\hline & $>21$ & 40 & 40 & \\
\hline
\end{tabular}

Sumber: Data Primer (diolah), Tahun 2018 


\section{Analisis Data}

\section{Pengujian Validitas}

Adapun hasil uji validitas dalam penelitian ini sebagai berikut:

Tabel 3.Hasil Pengujian Validitas Variabel Persepsi Konsumen

\begin{tabular}{|c|c|c|c|}
\hline Nomor & r hitung & r table & Keterangan \\
\hline Item1 & 0,485 & 0,163 & Valid \\
\hline Item2 & 0,458 & 0,163 & Valid \\
\hline Item3 & 0,533 & 0,163 & Valid \\
\hline Item4 & 0,629 & 0,163 & Valid \\
\hline Item5 & 0,385 & 0,163 & Valid \\
\hline Item6 & 0,495 & 0,163 & Valid \\
\hline Item7 & 0,469 & 0,163 & Valid \\
\hline Item8 & 0,572 & 0,163 & Valid \\
\hline Item9 & 0,513 & 0,163 & Valid \\
\hline Item10 & 0,395 & 0,163 & Valid \\
\hline
\end{tabular}

Sumber: Data primer (diolah), tahun 2018

Berdasarkan data pada tabel3 diatas, maka dapat disimpulkan bahwa semua item pertanyaan variabel persepsi konsumen dinyatakan valid.

Tabel 4.Hasil Pengujian Validitas Variabel Kualitas Produk

\begin{tabular}{|c|c|c|c|}
\hline Nomor & r hitung & r table & Keterangan \\
\hline Item1 & 0,403 & 0,163 & Valid \\
\hline Item2 & 0,288 & 0,163 & Valid \\
\hline Item3 & 0,381 & 0,163 & Valid \\
\hline Item4 & 0,331 & 0,163 & Valid \\
\hline Item5 & 0,691 & 0,163 & Valid \\
\hline Item6 & 0,546 & 0,163 & Valid \\
\hline Item7 & 0,520 & 0,163 & Valid \\
\hline Item8 & 0,397 & 0,163 & Valid \\
\hline Item9 & 0,542 & 0,163 & Valid \\
\hline Item10 & 0,502 & 0,163 & Valid \\
\hline
\end{tabular}

Sumber: Data primer (diolah), tahun 2018

Berdasarkan data pada tabel 4 diatas, maka dapat disimpulkan bahwa semua item pertanyaan variabel kualitas produk dinyatakan valid.

\section{Pengujian Reliabilitas}

Adapun hasil uji reliabilitas dalam penelitian ini sebagai berikut:

Tabel 5.Hasil Pengujian Reliabilitas

\begin{tabular}{|c|c|c|}
\hline Variable & Cronbach's Alpha & Ket \\
\hline Persepsi Konsumen & 0.655 & Reliable \\
\hline Kualitas Produk & 0.609 & Reliable \\
\hline
\end{tabular}

Sumber: Data primer (diolah), tahun 2018 
Hasil uji reliabilitas tersebut menunjukkan bahwa variabel persepsi konsumen dan kualitas produk mempunyai koefisien Alpha yang cukup besar sehingga dapat dikatakan reliabel layak digunakan sebagai alat ukur.

\section{Analisis Persamaan Regresi Linear Sederhana}

Analisis regresi digunakan untuk menguji hipotesis tentang pengaruh variabel bebas terhadap variabel terikat. Berdasarkan estimasi regresi sederhana dengan program SPSS diperoleh hasil seperti tabel berikut ini:

Tabel 6.Hasil Regresi Sederhana

\begin{tabular}{|c|c|c|c|c|c|}
\hline \multirow[t]{2}{*}{ Model } & \multicolumn{2}{|c|}{$\begin{array}{l}\text { Unstandardized } \\
\text { Coefficients }\end{array}$} & \multirow{2}{*}{$\begin{array}{c}\text { Standardized } \\
\text { Coefficients } \\
\text { Beta }\end{array}$} & \multirow{2}{*}{$\begin{array}{l}\mathrm{t} \\
\mathrm{B}\end{array}$} & \multirow{2}{*}{$\begin{array}{c}\text { Sig. } \\
\text { Std. } \\
\text { Error }\end{array}$} \\
\hline & B & $\begin{array}{l}\text { Std. } \\
\text { Error }\end{array}$ & & & \\
\hline $\begin{array}{ll}1 & \text { (Constant) } \\
& \text { Persepsi_Konsumen }\end{array}$ & $\begin{array}{r}24,740 \\
, 440\end{array}$ & $\begin{array}{r}3,738 \\
, 089\end{array}$ & ,447 & $\begin{array}{l}6,618 \\
4,952 \\
\end{array}$ & $\begin{array}{l}, 000 \\
, 000\end{array}$ \\
\hline
\end{tabular}

a Dependent Variable: Kualitas_Produk

Sumber: Data primer (diolah), tahun 2018

Berdasarkan tabel 6 dapat diketahui persamaan regresi yang terbentuk adalah:

$\mathrm{Y}=24,740+0,440 \mathrm{X}$

\section{Pengujian Hipotesis}

\section{Pengujian Korelasi (r)}

Ukuran yang menyatakan keeratan buhungan tersebut adalah koefisien korelasi atau sering disebut dengan korelasi person (pearson product moment). Hasil pengujian korelasi disajikan pada tabel berikut.

Tabel 7. Uji Korelasi (r)

\begin{tabular}{|ll|r|r|}
\hline & & Persepsi_Konsumen & Kualitas_Produk \\
\hline Persepsi_Konsumen & Pearson & 1 &, $447(* *)$ \\
& Correlation & &, 000 \\
& Sig. $(2$-tailed) & 100 & 100 \\
& $N$ &, $447(* *)$ & 1 \\
Kualitas_Produk & Pearson &, 000 & 100 \\
& Correlation & 100 & 1 \\
& Sig. $(2-$ tailed) & $N$ & \\
& $N$ & & \\
&
\end{tabular}

** Correlation is significant at the 0.01 level (2-tailed).

Sumber: Data primer (diolah), tahun 2018 
Berdasarkan tabel 7 diatas diperoleh angka $r$ sebesar 0,447. Hal ini menunjukkan bahwa terjadi hubungan yang sedang antara persepsi konsumen terhadap kualitas produk.Karena nilai $\mathrm{R}$ berada diantara 0,40 sampai dengan 0,599 dengan intepretasi koefisien kolerasi sedang.

\section{Uji Determinasi $\left(\mathbf{R}^{2}\right)$}

Koefisien determinasi merupakan besaran yang menunjukan besarnya variasi variabel dependen yang dapat dijelaskan oleh variabel independennya. Nilai koefisien determinasi ditentukkan dengan nilai $\mathrm{R}^{2}$ sebagaimana dapat dilihat pada tabel 8:

\section{Tabel 8.Koefisien Determinasi}

\begin{tabular}{|c|c|c|c|c|}
\hline Model & $\mathrm{R}$ & R Square & $\begin{array}{l}\text { Adjusted R } \\
\text { Square }\end{array}$ & $\begin{array}{l}\text { Std. Error of the } \\
\text { Estimate }\end{array}$ \\
\hline 1 & 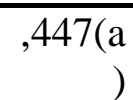 & ,200 & , 192 & 3,755 \\
\hline
\end{tabular}

a Predictors: (Constant), Kualitas_Produk

Sumber: Data primer (diolah), tahun 2018

Hasil perhitungan regresi dapat diketahui bahwa koefisien determinasi $\mathrm{R}^{2}$ yang diperoleh sebesar 0,200. Hal ini berarti 20,00\% variasi variabel kualitas produk dapat dijelaskan oleh variabel persepsi konsumen sedangkan sisanya sebesar 80,00\% diterangkan oleh variabel lain yang tidak dianalisis dalam penelitian ini.

\section{Uji t}

Untuk menguji pengaruh variabel bebas terhadap variabel terikat menggunakan uji t. Hasil perhitungan diperoleh sebagai berikut:

\section{Tabel 9.Hasil Uji t}

\begin{tabular}{|c|c|c|c|c|c|}
\hline \multirow[t]{2}{*}{ Model } & \multicolumn{2}{|c|}{$\begin{array}{l}\text { Unstandardized } \\
\text { Coefficients }\end{array}$} & \multirow{2}{*}{$\begin{array}{c}\text { Standardized } \\
\text { Coefficients } \\
\text { Beta } \\
\end{array}$} & \multirow{2}{*}{$\mathrm{t}$} & \multirow{2}{*}{$\begin{array}{c}\text { Sig. } \\
\text { Std. } \\
\text { Error } \\
\end{array}$} \\
\hline & B & Std. Error & & & \\
\hline $\begin{array}{ll}1 & \text { (Constant }) \\
& \text { Persepsi_Konsumen }\end{array}$ & $\begin{array}{l}24,740 \\
, 440\end{array}$ & $\begin{array}{l}3,738 \\
, 089\end{array}$ & ,447 & $\begin{array}{l}6,618 \\
4,952\end{array}$ & $\begin{array}{l}, 000 \\
, 000\end{array}$ \\
\hline
\end{tabular}

a. Dependent Variable: Kualitas_Produk

Sumber: Data primer (diolah), tahun 2018 
Berdasarkan tabel diatas dapat disimpulkan bahwa signifikansi t hitung sebesar 0.000 lebih kecil dari 0.05 , maka dapat dinyatakan bahwa ada pengaruh antara persepsi konsumen dengan kualitas produk mie goreng merek mie sedaap dan indomie di kecamatan Lais.

\section{Pembahasan}

Nilai koefisien regresi sebesar 0,440, artinya persepsi konsumen berpengaruh terhadap kualitas produk.Nilai koefisien regresi yang bersifat positif berarti terjadi hubungan yang searah antara persepsi konsumen dan kualitas produk.Setiap peningkatan dalam persepsi konsumenakan meningkatkan pula kualitas produk. Dengan demikian, apabila persepsi konsumen terhadap mie goreng merek mie sedaap dan mi indomie semakin baik dan positif maka dapat dipastikan konsumen akan memberikan loyalitasnya dengan terus mengkonsumsi mie instan. Akan tetapi untuk dapat mempertahankan dan meningkatkan persepsi positif konsumen mie instan juga harus terus mempertahankan dan meningkatkan kualitas produk yang diberikan.

Nilai koefisien korelasi sebesar 0,440, artinya terdapat korelasi yang sedang antara persepsi konsumsi dengan kualitas produk.Ini berarti setiap kelalaian dalam produk dapat menimbulkan kekecewaan yang sangat nyata pada konsumen.Oleh karena itu penting bagi Wings Food dan Indo Food untuk senantiasa mengevaluasi setiap kebijakan yang dijalankan, juga mengevaluasi setiap fitur-fitur produk yang ditawarkan kepada konsumen. Sedangkan nilai $R$ squaresebesar 0,200, artinya persepsi konsumen mempengaruhi kualitas produk sebesar $20 \%$. Ini berarti konsumen akan selalu menilai setiap indikator produk yang mereka terima, dan menjadikan hasil penilaian mereka sebagai patokan untuk tetap mengkonsumsi mie instan.

Nilai signifikansi uji t (t hitung) sebesar 0.000 lebih kecil dari nilai signifikansi $\alpha$ (0.05), membuktikan bahwa hipotesis yang dirumuskan sebelumnya dapat diterima.Hipotesis tersebut adalah "Persepsi konsumen diduga berpengaruh signifikan terhadap kualitas produk mie goreng merek mie sedaap dan mie indomie di kecamatan Lais".

Hasil penelitian ini sejalan dengan penelitian yang telah dilakukan sebelumnya oleh C Esti Susanti (2003) yang berjudul "Analisis Persepsi Konsumen Terhadap 
Kualitas Produk Keramik Merek Milan di Surabaya”. Hasil penelitian menunjukkan bahwa (1 ) Nilai total rata - rata persepsi konsumen surabaya terhadap variabel-variabel kualitas produk keramik Merek Milan sebesar 4.4138 dengan standar deviasi 0,61165. Hal ini berarti bahwa persepsi konsumen Surabaya terhadap variabel-variabel kualitas produk keramik merek Milan adalah baik. (2) Dari hasil nilai rata-rata masing-masing variable kualitas produk diketahui bahwa variabel kualitas yang mempunyai persepsi konsumen paling baik adalah variable Augmentedry pruduct. Dengan nilai rata-rata sebesar 4,765 dan dengan nilai standar deviasi terendah sebesar 0.4395 dan sejalan dengan penelitian Crentsil Kofi Agyekum, Huang Haifeng, Amma Agyeiwaa (2015) yang berjudul Consumer Perception of Product Quality. Hasil Penelitian menunjukkan bahwa persepsi kualitas berpengaruh positif signifikan terhadap keputusan pembelian. Konsumen memiliki ide yang berbeda atau persepsi pada kualitas produk berdasarkan usia mereka, tingkat pendapatan, dan, latar belakang pendidikan untuk mempengaruhi mereka pada kriteria yang digunakan dalam menentukan kualitas produk saat melakukan pembelian.

\section{SIMPULAN}

Dari pembahasan yang telah diuraikan, maka dapat ditarik simpulan sebagai berikut : 1) Berdasarkan hasil regresi diketahui nilai konstanta sebesar 24,740 artinya konstanta bertanda positif. Hal ini menunjukkan bahwa persepsi konsumen mempunyai hubungan yang positif terhadap kualitas produk. Koefisien kemampuan kerja memberikan nilai sebesar 0,440 yang berarti bahwa variabel persepsi konsumen bertambah satu satuan maka variabel kualitas produk bertambah sebesar 0,440. 2) Nilai r sebesar 0,447. Hal ini menunjukkan bahwa terjadi hubungan yang sedang antara persepsi konsumen terhadap kualitas produk. Karena nilai R berada diantara 0,40 sampai dengan 0,599 dengan intepretasi koefisien kolerasi sedang. 3) Hasil perhitungan regresi dapat diketahui bahwa koefisien determinasi $\mathrm{R}^{2}$ yang diperoleh sebesar 0,200 . Hal ini berarti $20,00 \%$ variasi variabel kualitas produk dapat dijelaskan oleh variabel persepsi konsumen sedangkan sisanya sebesar $80,00 \%$ diterangkan oleh variabel lain yang tidak dianalisis dalam penelitian ini. 4) Pengujian pengaruh variabel bebas secara bersamasama terhadap variabel terikatnya dilakukan dengan menggunakan uji t. Hasil 
perhitungan statistik menunjukkan nilai $\mathrm{t}$ hitung $=4,952$. Dengan menggunakan batas signifikansi 0,05, maka diperoleh nilai t hitung 4,952> dari 1,984. Maka Ho ditolak dan menerima Ha.Hal ini berarti bahwa hipotesis yang menyatakan variabel persepsi konsumen berpengaruh terhadap kualitas produk.

\section{DAFTAR PUSTAKA}

Agyekum, and Crentsil Kofi. 2015. Consumer Perception of Product Quality, China Journal Of Management and Economics Department. China: Beijing University of Tech

Arikunto, Suharsimi. 2012. Prosedur Penelitian Suatu Pendekatan Praktik dan Hipotesis Penelitian . Jakarta: Rineka Cipta

Baum, Feigan. 2011. Faktor yang Mempengaruhi Kualitas Produk. Jakarta: Erlangga

Indofood. 2009. Indomie Goreng.http://id.wikipedia.org/wiki/indomie

Kotler, Philip. 2012. Indikator Persepsi konsumen. Jakarta: Erlangga

Kotler, Philip dan Gary Amstrong. 2012. Definisi Kualitas Produk. Surabaya :Proxis Group.

Kuncoro, Mudrajad. 2012. Koefisien Determinasi. Jakarta: Erlangga.

Malhotra. 2013.Riset Pemasaran. Jakarta: Indeks

Nasir, Moh. 2012. Oprasional Variabel. Bogor: Ghalia Indonesia

Priyatno, Dwi. 2012. Uji Varibel Penelitian. Yogyakarta: Andi

Sugiyono. 2012. MetodePenelitian. Bandung: Alfabeta

Sunyoto, Danang. 2013. Dasar-dasar Manajemen Pemasaran. Yogyakarta: $\quad$ Caps Publising

Suryani, Tatik. 2012. Perilaku konsumen dan Implikasi pada Strategi Pemasaran. Jakarta: Graha Ilmu.

Susanti, C Esti. 2003. Analisis Persepsi Konsumen Terhadap Kualitas Produk Keramik Merek Milan di Surabaya. Surabaya:Jurnal Widya Manajemen \& Akuntansi Vol.3 No.02 2 Agustus 2003: 14 0-t5 9

Wings food. 2003. Mie sedaap goreng.http://id.wikipedia.org/wiki/mie_sedaap 